\title{
Radikal Sistektomi Sonrası Klinik Evre ve Patolojik Evre Uyumsuzluğu, Yüksek Evreye Neden Olan Faktörler ve Sonuçları
}

\section{Comparison of the Clinical and Pathologic Staging in Patients Undergoing Radical Cystectomy, the Factors Associated with Upstaging and its Effect on Outcome}

\author{
Dr. Polat Türker \\ Namık Kemal Üniversitesi Tıp Fakültesi, Üroloji Anabilim Dalı, Tekirdağ, Türkiye
}

\section{Özet}

Mesane kanseri klinik olarak olguların yaklaşık yarısında, olduğundan daha düşük evrelenmektedir. Son 25 yılda evrelemedeki bu hata oranının azalması yönünde belirgin bir gelişme olmamıştır. Radikal sistektomi sonrası evre yükselmesi gözlenen olgular, doğru evreleme yapılmış olgular ile karşılaştırıldıklarında daha yüksek rekürrens ve mesane kanserine bağı ölüm oranlarına sahiptirler. Günümüzde, radikal sistektomi öncesi organ dışı yayılım ve evre yükselmesi varlığını öngörebilecek güvenilir belirteçler henüz mevcut değildir. Farklı çalışmalarda; T2 evre hidronefroz, karsinoma in-situ, yüksek derece hastalık, lenfovasküler invazyon, kadın cinsiyet ve nötrofil-lenfosit oranı gibi değişkenler patolojik evre yükselmesi ile ilişkili bulunmuştur. (Üroonkoloji Bülteni 2014;13:84-87)

Anahtar Kelimeler: Üretelyal mesane kanseri, evre yükselmesi, klinik evreleme, patolojik evreleme

\begin{abstract}
Summary
Bladder cancer is clinically understaged in about half of the cases and no improvements in solving this problem has been observed during the past 25 years. Patients who are clinically upstaged after radical cystectomy have higher recurrence and bladder cancer mortality rates when compared to those who are correctly staged. Currently, reliable predictors of extravesical upstaging at the time of radical cystectomy do not exist. In various studies of T2 staging, hydronephrosis, carcinoma in situ, high-grade disease, lymphovascular invasion, female gender and neutrophil-lymphocyte ratio are found to be associated with upstaging. (Bulletin of Urooncology 2014;13:84-87)
\end{abstract}

Key Words: Urethelial bladder cancer, upstaging, clinical staging, pathological staging

\section{Giriş}

Mesane kanseri evrelemesi hem tedavi planlaması hem de hastalığın seyri hakkında bir öngörü yaparken kullandığımız en önemli sınıflama sistemidir. Genel olarak patolojik evre hastalığın seyri konusunda en doğru bilgiyi vermektedir fakat bu veriye ancak radikal sistektomi sonrası ulaşılabilinmektedir. 'Klinik evreleme', mesane tümörü transüretral rezeksiyon (TURM) örneğinin patolojik incelemesi, anestezi altında uygulanan bimanuel muayene ve görüntüleme yöntemleri (BT, MR gibi) ile gerçekleştirilmektedir (1). Teknolojideki ilerlemeye rağmen görüntülemeyöntemleri, hem primer tümörün evrelemesinde hem de nodal tutulumun gösterilmesinde halen yetersiz kalmaktadır (2). Klinik evreleme ve radikal sistektomi doku örneğinin patolojik incelenmesi sonrası tanımlanan 'patolojik evreleme' arasında uyumsuzluk beklenenden fazla olup, istenmeyen bir düşük klinik evreleme problemi mevcuttur. Bu problem hastaların zamanında ve doğru tedavi almasını engellemektedir.

TUR-M patolojisi ile radikal sistektomi patolojisi arasındaki uyumsuzluk oranı literatürdeki çalışmalarda \%20 ile \%80 arasında değişmektedir $(3,4,5,6,7,8)$. Svatek ve ark. literatürdeki en geniş serilerden biri olan 3,393 hastalık radikal sistektomi serilerinde; klinik evrenin yanlış olarak düşük evrelenme oranını \%50 olarak belirtmişlerdir (9). 'National Cancer Database' verileri incelenerek mesane kanseri nedeni ile 1998-2009 yılları arasında radikal sistektomi uygulanmış olan 16,953 hastanın dahil edildiği çok merkezli retrospektif çalışmada klinik evre ile patolojik evre arasında evre yükselmesi oranı \%41,9 olarak rapor edilmiştir (10). 
Malesef son 25 yılda evrelemedeki bu hata oranının azalması yönünde bir gelişme olmamıştır $(3,4,6)$. Bunun yanında son yıllarda şiddetle önerilen re-TUR uygulamasının bu problemde bir miktar düzelme sağlaması beklenmektedir $(11,12)$.

KiOMK'den Kasa İnvazif Mesane Tümörlerine Yükselme KIOMK'de radikal sistektomi sonrası kasa invazif olarak rapor edildiği evre yükselmesi en fazla cT1 evresindeki grupta beklenmektedir $(3,9)$. TUR ile klinik cT1 evre tanısı konan tümörlerde eğer radikal sistektomi uygulanırsa \%27\%51 oranında kasa invazyon gösterdiği ortaya konmuştur $(3,4)$. Bu olgular radikal sistektomiden doğru zamanda faydalanamamaktadırlar. Diğer bir yandan, 'Erken sistektomi' tedavisi uygulanan KIOMK tanılı hastalardan, radikal sistektomi patolojisinde kasa invazif rapor edilenlerin ( $\leq \mathrm{cT} 2$ 'den pT2'ye yükselme) sağkalım oranları, baştan kasa invaziv tümör olarak doğru evreleme ile radikal sistektomi uygulanan hastalara oranla daha kısa olarak bildirilmektedir $(13,14)$. Bu sonuçlar önemli oranda bir hasta grubunda erken radikal cerrahinin düşük klinik evreleme sebebi ile uygulanmadığını göstermekte, iyi bir TUR ve takibinde yüksek progresyon riski barındıran tümörlerde reTUR'un önemini bir kez daha vurgulamaktadir.

\section{Organa Sınırlıdan Organ Dışı Yayılımı Olan Mesane Kanserine Yükselme}

Patolojik olarak organa sınırlı mesane kanseri olgularında 10 yıllık sağkalım \%56 iken lenf nodu tutlumu olmayan fakat organ dışı yayılımı mevcut olan hastalar için \%27 olarak belirtilmektedir $(15,16)$. Klinik olarak cT2 tanısı olan olgular evre yükselmesinin en sık görüldüğü grup olup, evre yükselmesi sonrası en dramatik etki bu grupta izlenmektedir $(3,9)$. Klinik olarak organa sınırlı olarak evrelenen ( $\leq \mathrm{T} 2)$ olguların, radikal sistektomi sonrası \%32\%55 oranında organ dışı yayılım gösterdiği belirtilmektedir $(3,4,6,9)$.

Neoadjuvan kemoterapinin klinik T2-4aN0M0 evresindeki üretelyal mesane kanseri hastalarında \%5-\%8 oranında sağkalım avantajı sağladığı seviye 1 kanıt ile gösterilmiştir $(17,18)$. Bu tedavinin özellikle organ dışı yayılımı olan $(\geq T 3)$ olgularda daha etkin olduğu bilinmektedir (19). Malesef neoadjuvan tedavi günümüzde gereğinden daha az uygulanmakta, sebep olarak düşük evreli kanserler için fazladan sistemik tedavi verilmesi ve radikal sistektomi tedavisinin gecikmesi belirtilmektedir. Evre III mesane kanserlerli olguların sadece \%1,2'sinin neoadjuvan tedavi aldığı bildirilmektedir (20).

\section{Evre Yükselmesinin Sağkalım Oranları Üzerine Etkileri}

Radikal sistektomi sonrası evre yükselmesi gözlenen olgular, doğru evreleme yapılmış olgular ile karşılaştırıldıklarında daha yüksek rekürrens ve mesane kanserine bağlı ölüme sebep olmaktadırlar $(4,9)$. Özellikle organa sınırlı hastalıktan organ

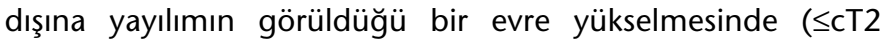
evreden pT3 veya LN pozitif hastalığa yükselme) sağkalımdaki kayıp daha da belirgin ortaya çıkmaktadır $(17,21)$.

Sağkalım oranlarındaki bu olumsuz etki, preoperatif T2 tanısı konan ve evre yükselmesi gösteren olgular ile evre yükselmesi göstermeyen olgular arasında (10 yıllık hastalığa bağlı yaşam süreleri oranları sırasıyla \%46 ve \%16 p<0,0001) olarak rapor edilmiştir (3). Klinik olarak organa sınırlı 1357 hastanın değerlendirdiği başka bir çalışmada; klinik evre, adjuvan radyoterapi, kemoterapi alımı ve patolojik değişkenler eşleştirilip karşılaştırma yapıldığında organa sınırlı olmayan evreye yükselmesi anlamlı olarak hastalık nüksü (HR: 3,5, \%95 $\mathrm{Cl}, 2,8-4,5, \mathrm{p}<0,001)$ ve kansere bağlı ölüm (HR: 3,5, \%95 Cl 2,6-4,6, $p<0,001$ ) ile ilişkili bulunmuştur (9).

Evre Yükselmesine ile ilişkili Risk Faktörleri: Evre Yükselmesi Öngörülebilir mi?

Mesane kanserinde evre yükselmesi yeni bir problem olmayıp bu konudaki etkin faktörleri ortaya koymak için birçok çalışma yapılmıştır. Farklı çalışmalarda; T2 evre hidronefroz, karsinoma in-situ, yüksek derece hastalık, lenfovasküler invazyon, kadın cinsiyet ve nötrofil-lenfosit oranı gibi değişkenler patolojik evre yükselmesi ile ilişkili bulunmuştur. Sistektomi öncesinde gerçek patolojiyi öngörmeye yarayabilecek matematiksel nomogramlar ve moleküler belirteçlerin geliştirilmesine yönelik çalışmalar da mevcuttur.

Karakiewicz ve ark. tarafından yayınlanan 2006 tarihli çok merkezli bir çalışmada, radikal sistektomi ve bilateral lenf nodu diseksiyonu uygulanan 726 olgu incelenmiştir (22). TUR ve sistektomi patolojilerinin birbiri ile uyumlu olma oranı \%35,7 olarak kaydedilmiştir. Çok değişkenli analizde yaş, TUR evresi, TUR derecesi ve eşzamanlı CIS; pT3-4 hastalık ile ilişkili olarak bulunmuştur. Organ dışı yayılım ve lenf nodu yayılımını öngörmeye yönelik klinik verilerle iki ayrı nomogram oluşturmuşlar, pT3-4 hastalığı öngörmede kendi nomogramları ve TUR'un doğruluk oranları karşılaştırıldığında sırasıyla \%75,7 ve \%71,4, pN1-3 hastalığı öngörmede ise yine TUR'a oranla sırasıyla \%63,1 ve \%61 olarak tespit etmişlerdir. Sonuç olarak çok değişkenli analizlere dayalı nomogramlar patolojik evreyi öngörmede çok yeterli olmasalar da TUR evrelemesinden daha doğru öngörü yaptıkları sonucuna varmışlardır.

Literatürdeki en geniş hasta sayılı seride çok değişkenli analizde evre yükselmesi ile ilişkili anlamlı değişkenler; kadın cinsiyet (OR 1,09, $p=0,031$ ), ileri yaş (OR 1,29, $\geq 80$ ile $<60$ yaşlar karşılaştırıldığında, $\mathrm{p}=0,001)$, patolojik incelenbilen lenf nodu sayısı (OR 1,87, $\geq 10$ LN ve sıfır LN karşılaştırıldığında, $p<0,001$ ), yüksek patolojik sınıf (grade), üretelyal kanser dışı kanser histolojisi ve ek olarak hidronefroz/hidroüreter varlığı (OR 1,65, $\mathrm{p}<0,001$ ) olarak tespit edilmiştir (10).

Mitra ve ark., neoadjuvan kemoterapi almamış ve klinik T2N0M0 mesane tümörü nedeni ile radikal sistektomi uygulanmış 948 hastalık çalışmalarında \%54 oranında evre yükselmesi tespit etmiş̧lerdir (23). TUR-m esnasındaki hastanın yaşı, hidronefroz varlığı, muskularis propria derin invazyonu ve lenfovasküler invazyon varlığı, tümörün sayısı ve büyüme paterni (papiller vs.) radikal sistektomi sonrası evre yükselmesi açısından anlamlı olarak bulunmuştur. Evre yükselmesi izlenen olgular izlenmeyenler ile karşılaştırıldıklarında nükssüz sağkalım ve tüm sağkalımın evre yükselmesi olan olgularda anlamlı olarak daha düşük bulunmuştur $(p<0,001)$. Bu veriler hangi hastada evre yükselmesi riskinin daha fazla olduğunu belirlemek amacı ile bir karar ağacı modeline yerleştirilip hastalar düşük, orta ve yüksek risk gruplarına ayrılmışlardır. Hidronefrozu bulunan \%70,6 olguda evre yükselmesi ve en kötü prognoz izlenmiştir $(p<0,001)$. Tümör büyüme paterni ve derin kas invazyonu ve hasta yaşı karar ağacındaki diğer faktörler olarak belirlenmiştir. Sonuç olarak hastaların bu faktörlerin varlığına göre sınıflandırılması neoadjuvan tedavi kararında faydalı olacağı belirtilmiştir.

Green ve ark., klinik olarak organa sınırlı olup sistektomi sonrası organ dışı yayılım göstermesi daha muhtemel olan 
hastaları belirlemek için bir nomogram geliştirmişlerdir (2). Tek merkezden 201 hastanın prospektif olarak dahil edildiği çalışmada çok değişkenli analizde evre yükselmesi için anlamlı olarak bulunan faktörler; TUR-m evresi TUR-m'de lenfovasküler invazyon varlığı, radyolojik olarak organ dışı yayılım varlığı veya hidronefroz varlığı olup nomogramdaki değiş̧enleri oluşturmuşlardır. Bu 3 değişken kullanılarak pT3/N (herhangi) veya $\mathrm{pT}$ (herhangi)/N+ tümörleri klinikte öngörebilecek bir nomogram oluşturulmuştur (AUC: 0,828 ).

Sayılan bu değişkenler dışında histolojik varyansın da evre yükselmesinde etkili olduğu gösterilmiştir (3). Toronto ve Turku olmak üzere iki merkezin katıldığı çalışmada 602 radikal sistektomi hastası inclenerek yapılan çok değişkenli analizde, histolojik varyans ( $\mathrm{HR}=2,77, \% 95 \mathrm{Cl}=1,6-4,8, \mathrm{p}<0,0001)$; ilk başvuruda T2 hastalığın bulunması $(p=0,001, O R=2,62, \% 95$ $C l: 1,44-4,77)$, yüksek sınıf tümörler $(p=0,01, O R=2,85, \% 95$ $\mathrm{Cl}: 1,21-6,7)$, lenfovasküler invazyon ( $p<0,001, \mathrm{OR}=5,17, \% 95$ $\mathrm{Cl}: 3,48-7,68)$ ve kadın cinsiyet $(\mathrm{p}=0,038, \mathrm{OR}=0,6, \% 95 \mathrm{Cl}: 0,38$ 0,97 ) organa sınırlı tümörden organ dışı yayılıma etki eden faktörler olara anlamlı olarak bulunmuştur.

Şimdiye kadar sayılan klinik verilere dayalı nomogramlar dışında Shariat ve ark. yakın zamanda yayınladıkları çalışmalarında, patolojik evre yükselmesini öngörmek amacı ile biyokimyasal belirteçlerin etkinliğini araştırmışlardır (24). Prospektif çalışmalarında organa sınırlı üretelyal mesane kanseri tanısı olup radikal sistektomi uygulanan 87 hastanın sistektomi öncesinde TUR patoloji örneklerinde p53, p21, p27, Ki67 ve siklin E1 imünohistokimyasal boyamalarını uygulamışlar, radikal sistektomi sonrası evre yükselmesi olan olgularda bu belirteçlerdeki değişiklikleri incelemişlerdir. Bu paneldeki belirteçlerin 2 'den fazlasındaki değişimi $T$ evre yükselmesi açısından bağımsız bir faktör olarak anlamlı bulunmuştur (HR:3,3, $p=0,024)$. Bu çalışmanın sonucuna göre böyle bir biyokimyasal belirteç paneli kullanılarak evre yükselmesi beklenen hastalar tespit edilmekte ve neoadjuvan kemoterapiden fayda görecek hasta grubu ortaya konmuş olmaktadır.

Birçok kanserde lökositoz ve artmış c-reaktif protein ile kendini gösteren sistemik inflamasyonun varlığı kötü prognoz ile ilişkili olarak bulunmuştur. Bu tip belirteçlerin varlığı tedaviye (cerrahi tedavi de dahil) cevabın düşük olacağına da işaret etmektedir. Benzer olarak nötrofil-lenfosit oranı da tümörün evresinden bağımsız olarak, mide, pankreas, kolorektal, akciğer, over, ve kolanjiyokarsinom ile ilişkili bulunmuştur (25). Yakın zamanda yayınlanan bir çalışmada bu oran mesane kanseri evre yükselmesini öngörebilecek bağımsız bir faktör olabileceği ileri sürülmüştür (26).

\section{Sonuç}

TUR patolojisi ve görüntüleme, üretelyal mesane kanseri prognozunu belirleme ve tedavi planlaması açısından en sık kullandığımız araçlardır. Fakat bu araçlar doğru evreleme için yetersiz olup mesane kanseri tanısı ile radikal sistektomi operasyonu uygulanan hastaların yaklaşık yarısında klinik evreden daha yüksek patolojik evre tespit edilmektedir. Bu yüksek orandaki uyuşmazlık hastaların uygun tedavi almasını, prognozun belirlenmesini engellemektedir. Evrelemedeki hatalar ile ilişkili faktörler ve bu hatanın öngörülebilmesi için yapılan çalışmalar sınırlı sayıdadır. Evre yükselmesi hastalığın progresyonu ve mesane kanserine bağlı ölüm riskini arttırmaktadır. Klinik evreleme esansında bu problem göz önünde tutulmalı, riski yüksek olan olgular sağkalım avantajı sağlayacak olan neoadjuvan kemoterapi kullanımı açısından tekrar değerlendirilmeli, evrelemeyi doğruluğunu arttıracak daha verimli araçlar için yeni çalışmalar yapılmalıdır. Bu amaçla Üroonkoloji Derneği'nin bünyesinde de çok merkezli bir çalışma başlatılmışır (27).

\section{Kaynaklar}

1. Bostroma Peter J, van Rhijn B, Fleshner N, et al. Staging and Staging Errors in Bladder Cancer. Eur Urol Suppl 2010;9:7

2. Green DA, Rink M, Hansen J, et al. Accurate preoperative prediction of non-organ-confined bladder urothelial carcinoma at cystectomy. BJU Int 2013;111:404-411.

3. Turker P, Bostrom PJ, Wroclawski ML, et al. Upstaging of urothelial cancer at the time of radical cystectomy: factors associated with upstaging and its effect on outcome. BJU Int 2012;110:804-811.

4. Shariat SF, Palapattu GS, Karakiewicz PI, et al. Discrepancy between clinical and pathologic stage: impact on prognosis after radical cystectomy. Eur Urol 2007;51:137-49; discussion 49-51.

5. McLaughlin S, Shephard J, Wallen E, et al. Comparison of the clinical and pathologic staging in patients undergoing radical cystectomy for bladder cancer. Int Braz J Urol 2007;33:25-31; discussion 31-32.

6. Svatek RS, Shariat SF, Novara G, et al. Discrepancy between clinical and pathological stage: external validation of the impact on prognosis in an international radical cystectomy cohort. BJU Int 2011;107:898-904.

7. Guzzo TJ, Magheli A, Bivalacqua T], et al. Pathological upstaging during radical cystectomy is associated with worse recurrence-free survival in patients with bacillus Calmette-Guerin-refractory bladder cancer. Urology 2009;74:1276-1280.

8. Cheng L, Neumann RM, Weaver AL, et al. Grading and staging of bladder carcinoma in transurethral resection specimens. Correlation with 105 matched cystectomy specimens. Am J Clin Pathol 2000;113:275-279.

9. Svatek RS, Shariat SF, Novara G, et al. Discrepancy between clinical and pathological stage: external validation of the impact on prognosis in an international radical cystectomy cohort. BJU Int 2011;107:898-904.

10. Gray PJ, Lin CC, Jemal A, et al. Clinical-pathologic stage discrepancy in bladder cancer patients treated with radical cystectomy: results from the national cancer data base. Int J Radiat Oncol Biol Phys 2014;88:1048-1056.

11. Grimm MO, Steinhoff C, Simon X, et al. Effect of routine repeat transurethral resection for superficial bladder cancer: a long-term observational study. J Urol 2003;170:433-437.

12. Divrik RT, Yildirim U, Zorlu F, Ozen H. The effect of repeat transurethral resection on recurrence and progression rates in patients with $\mathrm{T} 1$ tumors of the bladder who received intravesical mitomycin: a prospective, randomized clinical trial. J Urol 2006;175:1641-1644.

13. Zlotta AR, Fleshner NE, Jewett MA. The management of BCG failure in non-muscle-invasive bladder cancer: an update. Can Urol Assoc J.; 2009;3:S199-205

14. Lerner SP, Tangen CM, Sucharew $\mathrm{H}$, et al. Patterns of recurrence and outcomes following induction bacillus Calmette-Guerin for high risk Ta, T1 bladder cancer. J Urol 2007; 177:1727-1731.

15. Stein JP, Lieskovsky G, Cote R, et al. Radical cystectomy in the treatment of invasive bladder cancer: long-term results in 1,054 patients. J Clin Oncol 2001;19:666-675.

16. Shariat SF, Karakiewicz PI, Palapattu GS, et al. Outcomes of radical cystectomy for transitional cell carcinoma of the bladder: a contemporary series from the Bladder Cancer Research Consortium. J Urol 2006;176:2414-2422. 
Polat Türker

Radikal Sistektomi Sonrası Klinik Evre ve Patolojik Evre Uyumsuzluğu, Yüksek Evreye Neden Olan Faktörler ve Sonuçları

17. Grossman HB, Natale RB, Tangen CM, et al. Neoadjuvant Chemotherapy plus Cystectomy Compared with Cystectomy Alone for Locally Advanced Bladder Cancer. $N$ Engl J Med 2003;349:859-866.

18. Neoadjuvant chemotherapy in invasive bladder cancer: update of a systematic review and meta-analysis of individual patient data advanced bladder cancer $(A B C)$ meta-analysis collaboration. Eur Urol 2005;48:202-205.

19. Rosenblatt R, Sherif A, Rintala E, et al. Pathologic downstaging is a surrogate marker for efficacy and increased survival following neoadjuvant chemotherapy and radical cystectomy for muscleinvasive urothelial bladder cancer. Eur Urol 2012;61:1229-1238.

20. David KA, Milowsky MI, Ritchey J, et al. Low incidence of perioperative chemotherapy for stage III bladder cancer 1998 to 2003: a report from the National Cancer Data Base. J Urol 2007;178:451-454.

21. Clark PE. Neoadjuvant versus adjuvant chemotherapy for muscleinvasive bladder cancer. Expert Rev Anticancer Ther 2009;9:821-830.
22. Karakiewicz PI, Shariat SF, Palapattu GS, et al. Nomogram for predicting disease recurrence after radical cystectomy for transitional cell carcinoma of the bladder. J Urol 2006;176:1354-61.

23. Mitra AP, Skinner EC, Miranda G, Daneshmand S. A precystectomy decision model to predict pathological upstaging and oncological outcomes in clinical stage T2 bladder cancer. BJU Int 2013; 111:240-248.

24. Shariat SF, Passoni N, Bagrodia A, et al. Prospective evaluation of a preoperative biomarker panel for prediction of upstaging at radical cystectomy. BJU Int 2014;113:70-76.

25. McMillan DC. Systemic inflammation, nutritional status and survival in patients with cancer. Curr Opin Clin Nutr Metab Care 2009; 12:223-226

26. Potretzke A, Hillman L, Wong K, et al. NLR is predictive of upstaging at the time of radical cystectomy for patients with urothelial carcinoma of the bladder. Urol Oncol 2014.

27. www.uroonkoloji.org. 